\title{
Evaluation of the Phosphorus Adsorption Capacity of Natural Diopside in Aqueous Phosphoric Acid
}

\author{
Yuki Egami $^{1 *}$, Hata Soichiro ${ }^{1}$, Seiken Kato ${ }^{1}$, Sho Yamamoto $^{1}$ and Toru Nonami ${ }^{1}$ \\ ${ }^{1}$ School of Engineering, Chukyo University, 101-2 Yagotohonmachi, Showa-ku, Nagoya, Aichi Prefecture, Japan \\ * Corresponding auther:poke4789@gmail.com
}

In this study, the phosphorus adsorption ability of natural diopside in an aqueous solution of phosphoric acid was evaluated. The influence of calcium ions present in the aqueous solution and $\mathrm{pH}$ on the phosphorus adsorption capacity of diopside was investigated. Diopside was found to adsorb a significant amount of phosphorus in the calcium-rich solution. In addition, its phosphorus adsorption ability tended to improve in aqueous solutions with lower pHs. In such solutions, calcium was eluted to a large extent from diopside. The adsorption rate of phosphorus in an aqueous solution of diopside was highly correlated to calcium elution. For solutions with low $\mathrm{pH}$, the calcium bound to the $\mathrm{OH}$ group interacts with $\mathrm{H}^{+}$and the charge on diopside becomes more positive. With this increasing positive charge, it can more effectively adsorb the negatively charged phosphate ions. It was assumed that calcium reacts with the phosphate ions and forms calcium phosphate on the diopside surface. The amount of phosphorus adsorption is related to the elution of calcium from diopside. We also found that natural diopside could be used as a phosphorus adsorbent in aqueous solutions without the need for adding calcium or adjusting $\mathrm{pH}$.

Key words: Diopside, phosphorus, adsorption, calcium

\section{INTRODUCTION}

Most of the phosphorus reserves exist as phosphate ores, and, as with fossil fuels, depletion is becoming an important concern. In Japan, phosphorus is mainly used as chemical fertilizers and food additives. The phosphorus used as chemical fertilizers is discharged as waste to the sea and rivers, and is the main cause of water pollution problems such as red tide [1]. However, to maintain a steady supply of phosphorus, Japan is currently dependent on imports. Therefore, it is desirable to recover phosphorus from rivers and lakes for reuse.

Currently, phosphorus is recovered from sewage treatment plants. In the hydroxyapatite ((hereafter referred to as Hap) method, calcium chloride, sodium hydroxide, and adsorbent are added to sewage, and HAp is precipitated on the surface of the adsorbent to recover phosphorus. The Magnesium ammonium phosphate ((hereafter referred to as MAP) method adds magnesium and recovers phosphorus in the form of magnesium ammonium phosphate. The typical phosphorus recovery rates are $30 \%$ or more for the MAP method and $70 \%$ or more using the HAp method [2].

Diopside $\left(\mathrm{CaO} \cdot \mathrm{MgO} \cdot 2 \mathrm{SiO}_{2}\right)$ is a calcium magnesium silicate compound that easily dissolves calcium in aqueous solutions. It can be produced by solid-phase reaction or sol-gel methods. It is well-known that synthesized diopside elutes calcium in an aqueous solution and binds with phosphate ions on its surface to precipitate calcium phosphate as HAp [3-6].

Diopside also exists as a natural mineral that can be mined together and obtained relatively easily with iron. If this natural material can be applied as a phosphorus adsorbent, significant savings can be expected compared to using synthetic materials. Natural diopside adsorbed phosphorus can be directly applied to fields as fertilizers without adversely affecting the soil.

Therefore, in this study, the phosphorus adsorption ability of natural diopside was investigated in the presence or absence of calcium in a phosphoric acid solution. Furthermore, the influence of $\mathrm{pH}$ on the phosphorus adsorption ability of diopside was examined.

\section{EXPERIMENTAL METHODS}

2.1 Diopside samples

The natural diopside mineral mined in China (hereafter referred to as CND) and Brazil (BND) were used as natural diopside samples. Each was pulverized in a mortar to obtain a sample with a particle diameter of $53 \mu \mathrm{m}$ or less.

A total of $0.125 \mathrm{~mol}$ of calcium nitrate tetrahydrate (Wako Pure Chemical Industries, Ltd.), magnesium chloride hexahydrate (Wako Pure Chemical Industries, Ltd.), $0.125 \mathrm{~mol}$ of tetraethoxysilane (Kagaku Co., Ltd.), and $150 \mathrm{~mL}$ of ethanol were mixed using a sol-gel method. It was then fired at $650{ }^{\circ} \mathrm{C}$ and used as the artificial diopside sample (hereafter referred to as AD).

2.2 Qualitative and quantitative analysis of elements contained in natural minerals.

Qualitative analysis was performed by measuring the spectra of the CND and BND samples using a secondary target method with an energy dispersive X-ray fluorescence spectrometer (Rigaku Corporation; EDXL 300). A RX-9 (Rigaku Corporation; target crystal) made of copper and molybdenum was used as a secondary target.

The quantitative analysis of the major elements calcium, magnesium, and iron was performed by inductively coupled plasma (hereafter referred to as ICP) emission spectrometry with an ICP emission spectrometer 


\section{(SPECTRO BLUE FMX 26).}

2.3 Powder X-ray diffraction and scanning electron microscopy

The natural minerals, $\mathrm{AD}$ and their residues after phosphorus adsorption experiments were evaluated as follows.

Powder X-ray diffraction (XRD) measurements were performed using a powder X-ray diffractometer (Rigaku Corporation; MiniFLex). $\mathrm{Cu}$ was used for the X-ray tube and a $\mathrm{K} \alpha$ filter was used. The scanning speed was $2.00^{\circ} \mathrm{min}$, the sampling width was $0.01^{\circ}$, and the scanning range was 20 to $40^{\circ}$.

The surface properties of the materials were observed with a scanning electron microscope (SEM; JSM-IT 100, JEOL Ltd.). An energy dispersive X-ray analyzer (EDX) was attached to the scanning electron microscope, and elemental analysis on the surface was performed.

2.4 Phosphorus adsorption in phosphoric acid solution An aqueous solution was prepared by adjusting the phosphorus concentration to $100 \mu \mathrm{mol} / \mathrm{L}$ using potassium dihydrogen phosphate (Wako Pure Chemical Industries, Ltd.). Subsequently, $0.10 \mathrm{~g}$ of the diopside samples were placed in $100 \mathrm{~mL}$ of the prepared phosphoric acid solution and stirred for $1 \mathrm{~h}$. Afterwards, the phosphoric acid solution was filtered through a $0.20 \mu \mathrm{m}$ filter (Advantec Co., Ltd.: 25HP 020AN). The phosphorus concentration of the filtrate was then measured by the molybdenum blue method.

The phosphorus adsorption experiment with diopside in calcium doped phosphoric acid solution was also conducted. The aqueous solution was adjusted to a phosphorus concentration of $100 \mu \mathrm{mol} / \mathrm{L}$ and a calcium concentration of $1.0 \mathrm{mmol} / \mathrm{L}$. Then, $0.10 \mathrm{~g}$ of the diopside samples were mixed with $100 \mathrm{~mL}$ of the calcium-added phosphoric acid solution and stirred for $1 \mathrm{~h}$. The phosphorus concentration was then measured in the same manner as described above to determine the phosphorus adsorption ability of the sample.

2.5 Phosphorus adsorption in phosphate-buffered solutions at different $\mathrm{pH}$ values

A total of $10 \mathrm{~g}$ of CND was added to $100 \mathrm{~mL}$ of phosphate buffer solutions at $\mathrm{pH}$ 6, 7, and 8 (Wako Pure Chemical Industries, Ltd.) with a phosphorus concentration of $0.10 \mathrm{~mol} / \mathrm{L}$, and stirred for $1 \mathrm{~h}$. The phosphorus concentration was then measured as described above.

2.6 Measurement of calcium elution in aqueous solution A total of $0.10 \mathrm{~g}$ of CND was mixed in distilled water or citric acid buffer solution, and the calcium concentration of the solution after being stirred for $1 \mathrm{~h}$ was measured with an atomic absorption photometer $(Z-2300$ HITACHI).

\section{EXPERIMENTAL RESULTS}

3.1 Qualitative and quantitative analysis of elements contained in the natural minerals

From the qualitative analysis by fluorescent X-ray, both CND and BND contained mostly calcium, magnesium, silicon, iron, aluminum, and potassium.

As shown in Table I, both CND and BND contained mainly calcium, magnesium, and silicon, as determined by ICP. The molar ratio of calcium:magnesium:silicon was determined to be 1.0:0.8:1.95 for CND and 1.0:1.0:2.1 for BND. Not all of these elements constitute diopside, but the ratio is close to the theoretical composition of diopside (1:1:2). Also, assuming that all of these elements originated from diopside, the CND and BND samples contain approximately $90 \%$ diopside.

\subsection{Identification of natural minerals and synthetic} diopside

The XRD patterns of the synthetic diopside and natural minerals are shown in Figs. 1-3. The diffraction patterns of both samples coincided with that of the diopside reference. The half width of the diopside diffraction pattern of BND is smaller than those of CND and AD, indicating relatively high crystallinity. In CND, the peak intensity of quartz on the $\left(\begin{array}{lll}0 & 1 & 1\end{array}\right)$ plane near the diffraction angle of $26.5^{\circ}$ and that of diopside on the $\left(\begin{array}{lll}0 & 2 & 1\end{array}\right)$ plane was strong, suggesting that the natural mineral is a mixture of quartz and diopside. The CND and BND samples were used for phosphorus adsorption experiments.

Table I Quantitative analysis of the main components of the natural minerals by ICP luminescence analysis ( $\mathrm{wt} \%$ )

\begin{tabular}{lllll}
\hline & $\mathrm{Ca}$ & $\mathrm{Mg}$ & $\mathrm{Si}$ & $\mathrm{Fe}$ \\
\hline $\mathrm{CND}$ & 15.7 & 7.7 & 22.0 & 0.17 \\
$\mathrm{BND}$ & 16.3 & 10.6 & 24.3 & 0.36 \\
\hline
\end{tabular}

3.3 Phosphorus adsorption in phosphoric acid solution

The results of the phosphorus adsorption experiment where the Diopside sample was mixed in solution are shown in Fig. 4. The phosphorus adsorption rate of the diopside in the calcium-added phosphoric acid solution is also shown. All samples adsorbed phosphorus although there was a difference in the adsorption amount. AD exhibited an excellent phosphorus adsorption rate of approximately $90 \%$. This is likely due to the high purity of the synthetic diopside. The synthesis of AD at high temperatures resulted in superior phosphorus adsorption ability and agreed with previous reports [3]. Conversely, CND and BND adsorb phosphorus at a rate of 10 to $20 \%$ even in phosphoric acid solution without calcium addition. This is sufficiently effective adsorption for recovery of phosphorus from sewage. In addition, the phosphorus adsorption rate of all diopside samples improved by $2 \%$ to $7 \%$ in the calcium-added solution.

The relationship between the amount of calcium eluted from the CND and the phosphorus adsorption rate of CND is shown in Fig. 5. Diopside with a large amount of calcium eluted tended to adsorb more phosphorus. This tendency was the same whether in a phosphoric acid solution with or without calcium.

Ideally, calcium elution from the CND should be measured in phosphoric acid solution, but calcium eluted from the CND may react with phosphorus to form a precipitate. Therefore, it is impossible to accurately measure the elution. Therefore, in this experiment the amount of calcium eluted from CND was measured in distilled water. 


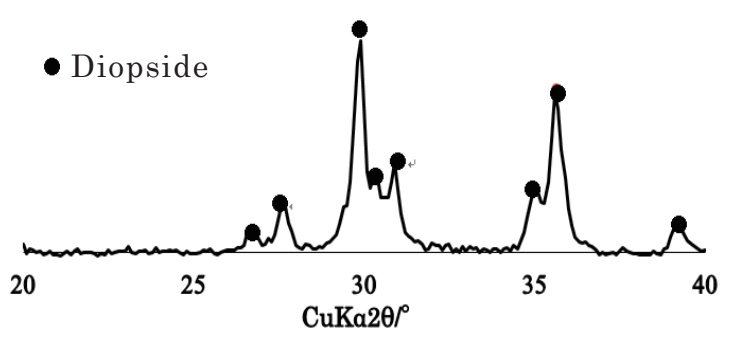

Fig. 1 XRD pattern of AD

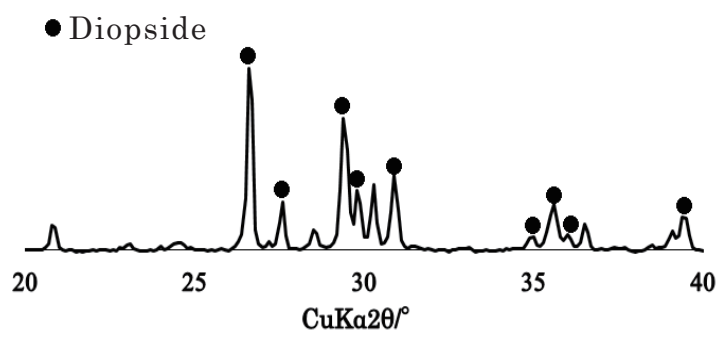

Fig. 2 XRD pattern of CND

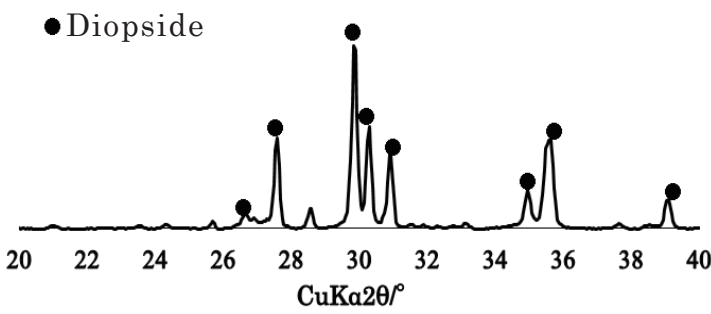

Fig. 3 XRD pattern of BND

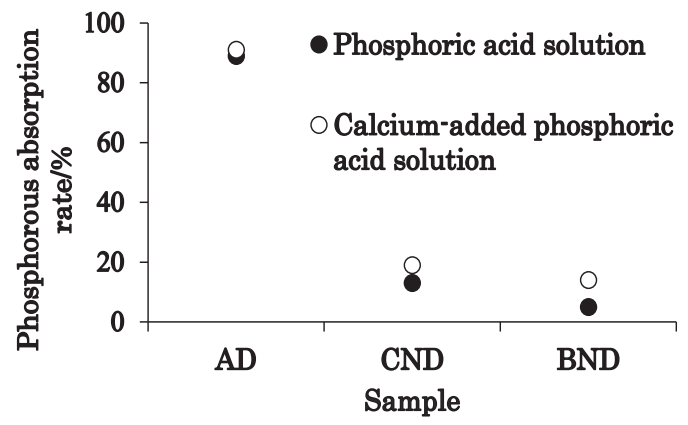

Fig. 4 Phosphorus adsorption rate (\%) of each diopside sample in a phosphoric acid solution with and without calcium (after stirring for $1 \mathrm{~h}$ ).

3.4 Phosphorus adsorption in phosphate buffer at various $\mathrm{pH}$

Figure 6 shows the results of the CND phosphorus adsorption experiments in phosphate buffers at different $\mathrm{pH}$. The CND adsorbed more phosphorus as the $\mathrm{pH}$ of the solution was lowered. With changing $\mathrm{pH}$, there was a difference of $2 \%$ to $9 \%$ in the phosphorus adsorption of CND.

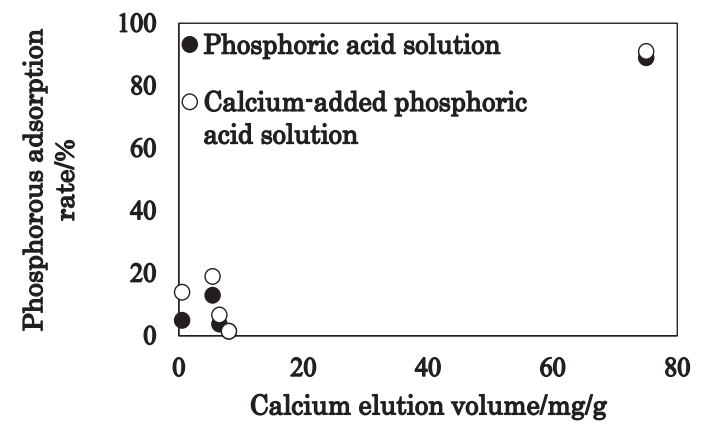

Fig. 5 Relationship between the calcium elution $(\mathrm{mg} / \mathrm{g})$ from the CND in distilled water and phosphorus adsorption rate (\%) of CND in a phosphoric acid solution.

Figure 7 shows the amount of calcium eluted from the CND in a citric acid solution at various $\mathrm{pH}$. As the $\mathrm{pH}$ of the citric acid solution was lowered, a greater amount of calcium was eluted from the CND. In this experiment, accurate determination of calcium elution could not be measured in a phosphoric acid solution. For this reason, the amount of calcium eluted from CND was measured in citrate buffer of different $\mathrm{pH}$ without phosphate ions.

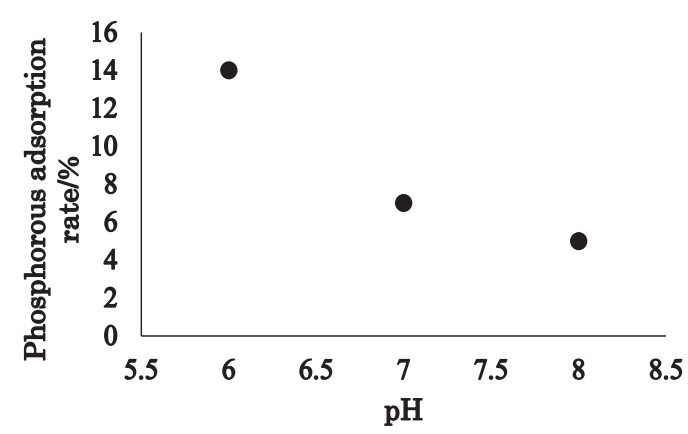

Fig. 6 Relationship between the $\mathrm{pH}$ of the phosphate buffer and phosphorus adsorption rate (\%) of CND (after stirring for $1 \mathrm{~h}$ ).

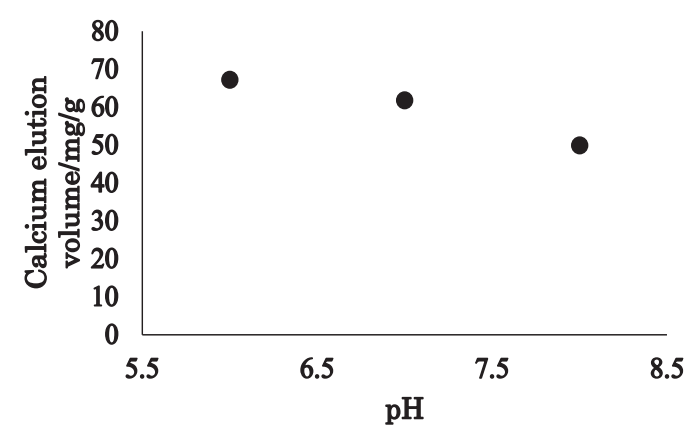

Fig. 7 Relationship between the $\mathrm{pH}$ of the citric acid solution and calcium elution $(\mathrm{mg} / \mathrm{g})$ from CND.

\section{DISCUSSION}

4.1 Phosphorus adsorption of natural diopside (CND)

Phosphoric acid exists in two chemical forms, $\mathrm{H}_{2} \mathrm{PO}_{4}$ and $\mathrm{HPO}_{4}{ }^{2-}$ in the solutions used in this study [7-8]. It is likely that calcium bonded with the $\mathrm{OH}^{-}$, as shown in formula (I), and interacts with $\mathrm{H}^{+}$in solution, increasing the positive charge. $(\mathrm{X}$ in the chemical formula is a metal 
ion, but in the case of this study it is $\mathrm{Ca}$ )

$$
\begin{aligned}
\text { (I) } \mathrm{X}-\mathrm{OH}+\mathrm{H}^{+} & \rightarrow \mathrm{X}-\mathrm{OH}_{2}^{+} \\
\text {(II) } \mathrm{X}-\mathrm{OH}_{2}^{+}+ & \mathrm{H}_{2} \mathrm{PO}^{-} \rightarrow \mathrm{X}_{-}-\mathrm{OH}_{2}^{+} \cdot \mathrm{H}_{2} \mathrm{PO}^{-} \\
\rightarrow & \mathrm{Ca}-\mathrm{H}_{2} \mathrm{PO}_{4}+\mathrm{H}_{2} \mathrm{O} \\
\text { (III) } \mathrm{X}-\mathrm{OH}_{2}^{+}+ & \mathrm{HPO}^{2-} \rightarrow \mathrm{X}_{-}-\mathrm{OH}_{2}^{+} \cdot \mathrm{HPO}^{2-} \\
& \rightarrow \mathrm{X}^{-} \mathrm{PO}_{4}^{+}+\mathrm{H}_{2} \mathrm{O}
\end{aligned}
$$

With respect to equations (II) and (III), it is assumed that calcium with an increased positive charge attracts the negatively charged phosphate ions and bind strongly.

In the phosphoric acid solution with calcium, the phosphorus adsorption rate of diopside was improved. Furthermore, the diopside adsorbs more phosphorus as the amount of calcium in the solution increases. It has been previously reported that phosphorus can be adsorbed on volcanic ash soil, which is composed of the same natural mineral [9].

Diopside adsorbs a large amount of phosphorus in a phosphate buffer solution at low $\mathrm{pH}$. Diopside eluted more calcium when placed in a lower $\mathrm{pH}$ solution. Therefore, the calcium concentration is high in a solution with low $\mathrm{pH}$. Furthermore, under acidic conditions, more $\mathrm{H}^{+}$is present, biasing reaction (I) to the right side of the equilibrium, allowing diopside to adsorb more phosphorus.

There was a strong correlation between calcium elution from diopside and its phosphorus adsorption rate, as shown in Fig. 8. The $\mathrm{pH}$ of the solution significantly affects the phosphorus adsorption ability of diopside, since the amount of calcium eluted varied depending on the $\mathrm{pH}$. It is thought that the eluted calcium reacts with phosphorus in the solution near the diopside surface, precipitating calcium phosphate, which decreases the amount of phosphorus in solution.

Since the calcium concentration increases in the calcium-added phosphoric acid solution, it is likely that calcium phosphate formed. Therefore, the phosphorus adsorption rate of the diopside increased in the calciumadded phosphoric acid solution.

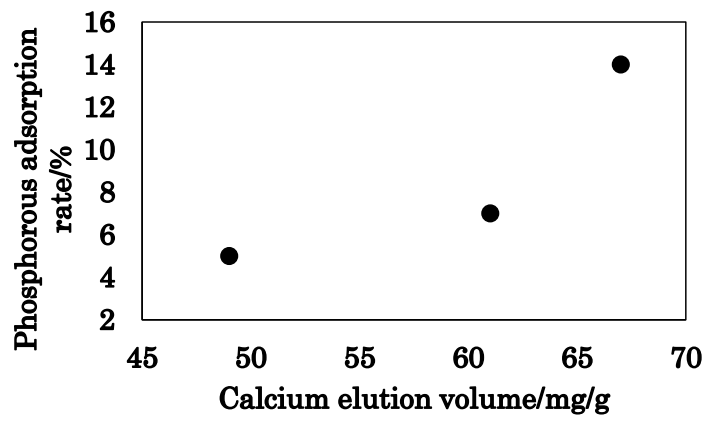

Fig. 8 Relationship between calcium elution $(\mathrm{mg} / \mathrm{g})$ from CND in a citrate buffer solution and phosphorus adsorption rate (\%) of CND in a phosphate buffer solution.

As mentioned above, diopside can adsorb phosphorus by eluting calcium in solution. Natural diopside was found to be inferior to synthetic diopside, but has sufficient phosphorus adsorption ability to be used as a phosphorus removing agent for sewage. It acts as a seed crystal which adsorbs phosphorus without adding calcium. In terms of cost, natural diopside is more practical than artificial diopside for the recovery of phosphorus from large volumes of sewage.

Natural diopside was found to adsorb phosphorus in a calcium free solution at $\mathrm{pH}$ 6-8. Because standard wastewater $\mathrm{pH}$ ranges from 5.8 to 8.6 , the adsorbent can be successfully applied to general sewage. For future practical application, it is necessary to evaluate the phosphorus adsorption ability in the presence of ion suppressants and the desorption of adsorbed phosphorus.

\section{CONCLUSIONS}

The ability of natural diopside to adsorb phosphorus in a phosphoric acid solution was investigated. The effect of calcium in a phosphoric acid solution and $\mathrm{pH}$ on phosphorus adsorption rate was evaluated. The following conclusions can be made.

(1) Diopside eluted more calcium as the $\mathrm{pH}$ of the citrate buffer solution was lowered. Diopside adsorbed more phosphorus with lower $\mathrm{pH}$ of the phosphorus buffer solution. Therefore, calcium is likely present in a large amount in the solution, especially in the vicinity of the diopside surface, allowing increased adsorption of phosphorous. With lower $\mathrm{pH}$, calcium bound to the $-\mathrm{OH}$ group and subsequently incorporated $\mathrm{H}^{+}$. Thus, it is assumed that calcium with an increased positive charge attracts the negatively charged phosphate ions and adsorbs phosphorus.

(2) There was a strong correlation between calcium elution in distilled water and the phosphorus adsorption rate in a phosphoric acid solution. Furthermore, when calcium was added to the solution, the phosphorus adsorption rate of diopside increased. In other words, if the calcium concentration increases near the diopside surface, calcium reacts with phosphorus, precipitating calcium phosphate and decreasing the concentration of phosphorus in solution. Natural diopside has potential as a phosphorus adsorbent for sewage that does not require the addition of calcium.

\section{REFERENCES}

[1] M. Tsurumaki, M. Watanabe, S. Tokairin, and Y. Yagi, Environ. Sys. Res., 36, 217-225 (2008).

[2] F. Kato, M. Takaoka, K. Oshita, and N. Takeda, J. JSCE, 63, 413-424 (2007).

[3] S. Yamamoto, T. Nonami, H. Hase, and N. Kawamura J. Aust. Ceram. Soc., 48, 180-184 (2012).

[4] T. Nonami, Y. Miake, K. Ozaki, and H. Ohsato, J. Dent. Res., 8, 85-92 (1995).

[5] T. Nonami, C, Takahashi, and J. Yamazaki, J. Ceramic Soc. Japan, 103, 703-708 (1995).

[6] T. Nonami and N. Satoh, J. Ceramic Soc. Japan, 103 , 804-809 (1995).

[7] H. Monma, Inorg. Mater., 3, 607-614 (1996).

[8] Y. Kato and I. Matsuoka, J. MMIJ, 107, 627-632 (1991).

[9] T. Mitani, A. Ichimura, K. Shimomura, H. Ohshiro, T. Yanagita, and Y. Jiang, J. Chem. Eng. Japan, 26, 877-881 (2000).

(Received January 9, 2018; Accepted February 5, 2018; Published Online April 1, 2018) 